
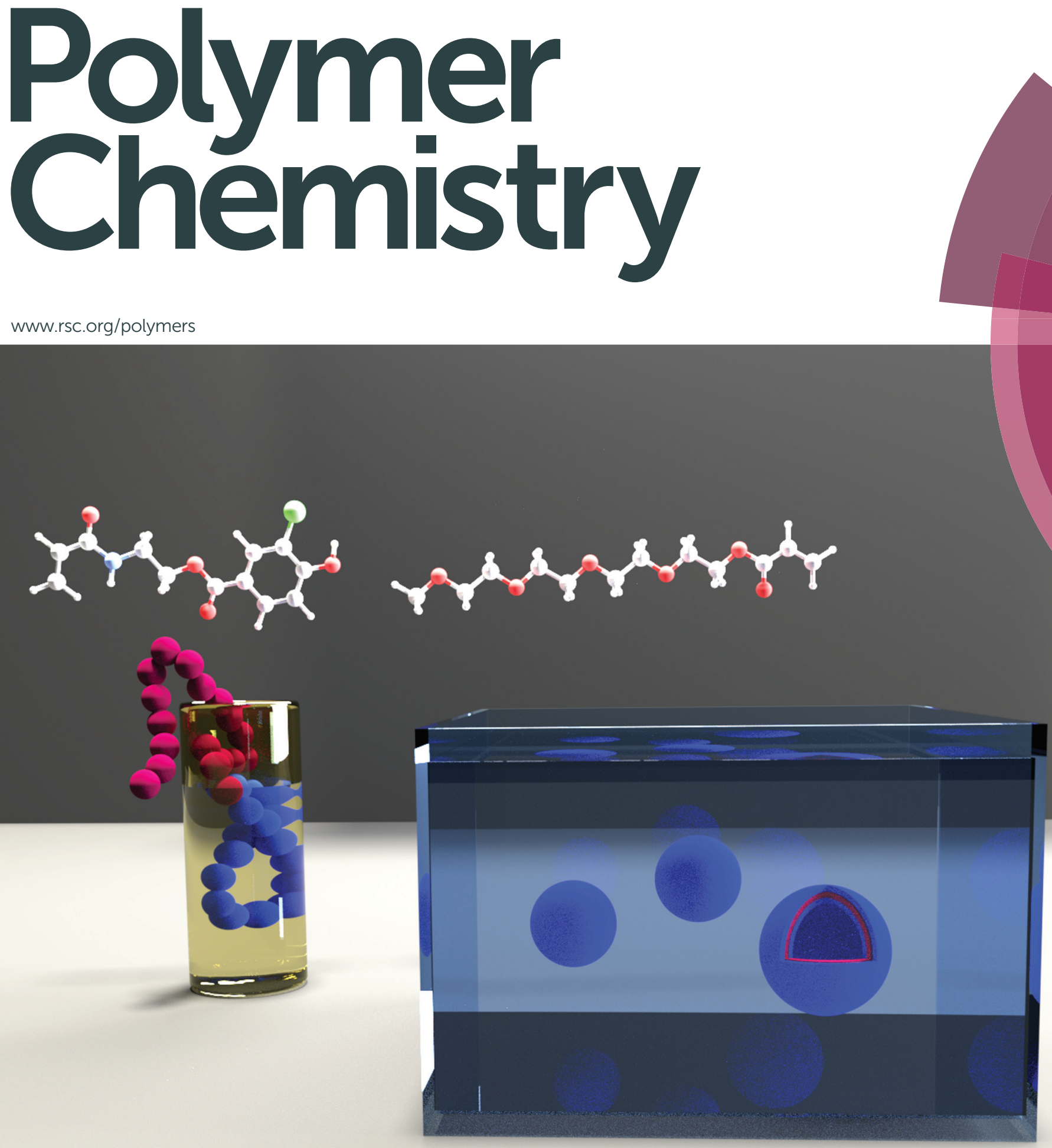


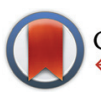

CrossMark $\leftarrow$ click for updates

Cite this: Polym. Chem., 2016, 7, 6714

Received 25th July 2016,

Accepted 19th September 2016

DOI: $10.1039 / c 6 p y 01292 b$

www.rsc.org/polymers

\section{One-pot RAFT and fast polymersomes assembly: a 'beeline' from monomers to drug-loaded nanovectors'}

\author{
F. Mastrotto, ${ }^{a}$ A. F. Breen, ${ }^{\text {a }}$ G. Sicilia, ${ }^{\text {a }}$ S. Murdan, ${ }^{\text {b A. D. Johnstone, }}{ }^{\text {C G. E. Marsh, }}{ }^{\text {' }}$ \\ C. Grainger-Boultby, ${ }^{a}$ N. A. Russell, ${ }^{c}$ C. Alexander ${ }^{a}$ and G. Mantovani ${ }^{\star a}$
}

\section{Introduction}

Polymersomes ${ }^{1}$ are vesicular assemblies formed from amphiphilic block copolymers, which have rapidly emerged as an important class of nanomaterials, with range of potential applications which include drug delivery, diagnostics and bioimaging. ${ }^{2-4}$ To date, polymersomes have been the subject of over 500 papers, with at least 11 patents filed within the last two years. ${ }^{5}$ Compared to phospholipid vesicles, polymersomes typically possess improved membrane stability, as well as superior tuneability of surface chemistry and structural parameters. ${ }^{6}$

An increasingly large area of research is focussed on the use of polymersomes as drug nanovectors in drug delivery. ${ }^{7-10}$ Recently, Battaglia and coworkers showed delivery of an IgG model cargo to the Central Nervous System (CNS) parenchyma

\footnotetext{
${ }^{a}$ School of Pharmacy, University of Nottingham, Nottingham NG7 2RD, UK. E-mail: giuseppe.mantovani@nottingham.ac.uk; Fax: +44 (0)115 846 6296; Tel: +44 (o) 01158232348

${ }^{b}$ Department of Pharmaceutics, UCL School of Pharmacy, University College London, 29-39 Brunswick Square, London, WC1N 1AX, UK

${ }^{c_{F}}$ Faculty of Engineering, University of Nottingham, Nottingham NG7 2RD, UK $\dagger$ Electronic supplementary information (ESI) available. See DOI: 10.1039/ c6py01292b
}

and CNS cells mediated by poly(2-diisopropylamino)ethyl methacrylate)-based $\mathrm{pH}$-responsive polymersomes functionalized with LRP-1-targeting Angiopep-2 and Rabies Virus Glycoprotein (RVG) peptide ligands to facilitate transport through the blood-brain barrier. ${ }^{11}$

Polymersomes have also been utilised to create nanosized reactors, where entrapped (bio)molecules - e.g. enzymes - are part of multicompartmental arrangements mimicking those found in cell organelles. In an early work Meier and coworkers incorporated $\beta$-lactamase within PDMS-PMOXA triblock copolymer vesicles. ${ }^{12}$ The introduction of a channel-forming protein from the outer cell wall of Gram-negative bacteria (OmpF) into the vesicle membrane allowed passive transport of ampicillin, an enzyme substrate, which was converted in the polymersome aqueous lumen into ampicillinoic acid. Lecommandoux and van Hest engineered multicompartimentalised polymersomes-in-polymersomes systems, mimicking artificial cells and cell organelles. ${ }^{13}$ These studies, in conjunction with the potential for self-propulsion, ${ }^{14}$ make polymersomes ideal candidates for the development of polymeric protocells. ${ }^{15,16}$

In terms of their manufacturing, polymersomes are often assembled from amphiphilic block copolymers synthesised through long synthetic procedures - typically at least two 
sequential polymerisations, requiring purification of both polymer intermediates and final amphiphilic macromolecules from unreacted monomers and traces of other low molecular weight impurities. Importantly, polymerisation reactions often need to be stopped at moderate monomer conversions to ensure high proportion of chain-end fidelity, which is required for subsequent polymer chain-extension. ${ }^{17-19}$

In addition to being not fully efficient, this approach invariably results in waste of functional monomers utilised for the polymerisation step, which is undesirable especially when these are particularly expensive, not commercially available, or both. Finally, the processes for the assembly of polymersomes are not always trivial. ${ }^{20}$ Although a range of techniques have been developed, ${ }^{21}$ most methods still suffer from low reproducibility and poor scalability, which may complicate industrial application of polymersomes. ${ }^{6}$ Whilst chemists are increasingly focussing on developing more efficient and greener chemical transformations - i.e. as described by Sharpless and coworkers' click chemistry philosophy - one could envisage that analogous approaches could be applied not only to individual chemical reactions, but also to entire processes. A clear move in this direction is the work on polymerization-induced self-assembly (PISA) by Armes' group and others, ${ }^{22-30}$ where block copolymers nano-objects can be assembled with predictable shape and size during the polymerisation process, by judicious choice of monomers and variation of polymer physicochemical characteristics (e.g. packing parameter $P){ }^{31}$

In the present work we aimed to develop a route to selfassembled drug nanovectors which would complement the range of applications inherent to PISA. In this case, drugloaded nanovesicles are engineered by sequential and quantitative polymerisation of appropriate monomers in one pot, followed by self-assembly of the resulting amphiphilic block copolymers into vesicles, by directly adding the final reaction mixture to a suitable aqueous phase (Chart 1). Key advantages of this approach include the avoidance of intrinsically inefficient purifications of polymer intermediates, the potential for incorporating a wide range of drugs - including those not com- patible with radical polymerisation conditions, and, similarly to PISA, facile assembly of nanovectors directly from the polymerisation solution, but without having to remove excess unreacted monomers.

For the polymerisation step, recent studies by Perrier and co-workers showed that well-defined multiblock copolymers can be obtained by RAFT polymerisation in one pot by sequential and quantitative polymerisation of suitable monomers in only a few hours ${ }^{18,32,33}$ or even minutes. ${ }^{34}$ The monomers were selected based on previous studies, where we showed that block copolymers based on novel pH-responsive monomers bearing substituted aromatic alcohols could be effectively assembled into well-defined nanovesicles, whilst incorporating specific drugs with high efficiency. ${ }^{35,36}$

\section{Experimental}

\section{Materials}

Terbinafine free base was extracted from a basic aqueous solution of terbinafine hydrochloride (Sigma-Aldrich $\geq 98 \%$ ) with dichloromethane (see ESI $\uparrow$ ). VA-044 was purchased from Wako Pure Chemical Industries Ltd. All the other solvents and reagents were purchased from Sigma-Aldrich or Fisher Scientific and used as received. Spectra/Por 8 kDa MWCO and SnakeSkin 3.5 kDa MWCO dialysis tubing were obtained from Fisher Scientific and VWR International, respectively. Cellulose membranes $(0.45$ and $0.22 \mu \mathrm{m})$ were purchased from Merck Millipore. ${ }^{1} \mathrm{H}^{-13} \mathrm{C}$ HSQC NMR experiments were carried out to facilitate peaks assignment. Yields were not optimized.

Synthesis of 2-(acryloyloxy)ethyl 3-chloro-4-hydroxybenzoate $(\mathrm{ACH}, 2)$ and 2-(3-chloro-4-hydroxybenzamido)ethyl acrylate (CHB, 3). The synthesis of the acrylic ACH (2) and acrylamide CHB (3) monomers was carried out by reaction of 3-chloro-4hydroxybenzoic acid with 2-hydroxyethyl acrylate (HEA) or $N$-hydroxyethyl acrylamide (HEAM), respectively. The typical procedure is described here for the synthesis of ACH (2) monomer. A solution of DCC $(17.1 \mathrm{~g}, 82.7 \mathrm{mmol})$ in anhydrous

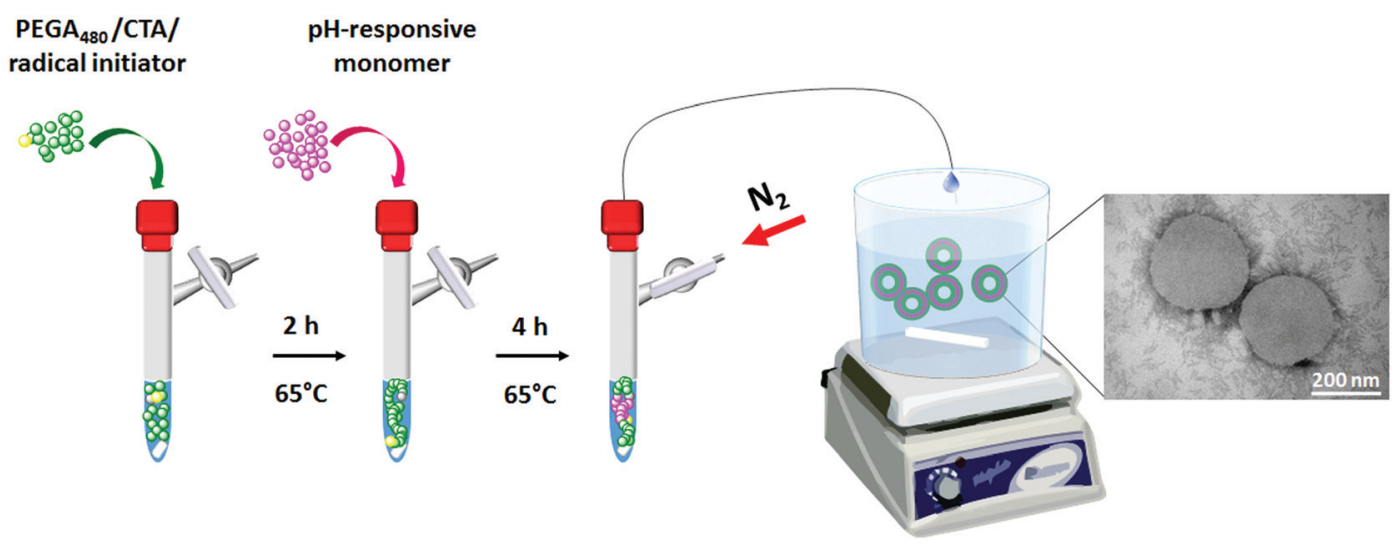

Chart 1 In line engineering of $\mathrm{mPEGA}_{12 a}-b-\mathrm{ACH}_{36}$ or $\mathrm{mPEGA}_{12 a}-b-\mathrm{CHB}_{36}$ polymeric vesicles via one-pot RAFT and in line post-polymerisation assembly. 
$\mathrm{CH}_{2} \mathrm{Cl}_{2}(100 \mathrm{~mL})$ was added dropwise and under stirring to a solution of 3-chloro-4-hydroxybenzoic acid (10.0 g, $55.1 \mathrm{mmol}$ ) and DMAP (0.256 g, $2.09 \mathrm{mmol})$ dissolved in 2-hydroxyethyl acrylate $(63.3 \mathrm{~mL}, 551 \mathrm{mmol})$, over 30 minutes The reaction mixture was stirred at room temperature for 16 hours, and the resulting dicyclohexylurea (DCU) precipitate was removed by filtration. The solvent was removed under reduced pressure, the resulting residue dissolved in $\mathrm{MeOH}$, and the monomer precipitated in deionized water at $\mathrm{pH} 5.0$ to remove most of the excess of HEA. The precipitate was isolated by centrifugation, redissolved in $\mathrm{CH}_{2} \mathrm{Cl}_{2}(\mathrm{ca} .150 \mathrm{~mL})$ and the resulting solution was dried over $\mathrm{MgSO}_{4}$, filtered, and the solvent removed under reduced pressure. The crude product was purified by flash chromatography (silicagel 60, 35-70 $\mu \mathrm{m}, \mathrm{CH}_{2} \mathrm{Cl}_{2}$ / EtOAc $9.5: 0.5 \mathrm{vol} / \mathrm{vol})$. Evaporation of the solvent from the relevant fractions yielded the desired monomer ACH (2) as a white solid. CHB (3) was synthesised using THF instead of $\mathrm{CH}_{2} \mathrm{Cl}_{2}$ as the solvent and was purified by flash chromatography (silicagel 60, 35-70 $\mu \mathrm{m}$, eluents $\mathrm{CH}_{2} \mathrm{Cl}_{2} /$ EtOAc, gradient $9.5: 0.5$ to $1: 1, \mathrm{vol} / \mathrm{vol})$.

ACH (2). 13.6 g, $50.1 \mathrm{mmol}$, Yield: 90.9\%. ESI-TOF mass spectrometry: expected $\mathrm{m} / \mathrm{z}$ for $[\mathrm{M}-\mathrm{H}]^{-}$269.02, found 269.02 Da FT-IR: $\nu$ 3330, 2937, 1716, 1686, 1601, 1580, 1455, 1411, 1363, 1251, 1186, 1072, 1023, 966, 936, 897, 833, 810, 760, $709 \mathrm{~cm}^{-1} .{ }^{1} \mathrm{H}$ NMR (400 MHz, $\left.\mathrm{CDCl}_{3}, \delta, \mathrm{ppm}\right): 4.47-4.55(\mathrm{~m}$, $4 \mathrm{H}, \mathrm{CH}_{2}$ ), 5.88 (dd, $J=10.4,1.4 \mathrm{~Hz}, 1 \mathrm{H}, \mathrm{CH}=\mathrm{CH} H$ ), 6.14 (dd, $\left.J=17.3,10.4 \mathrm{~Hz}, 1 \mathrm{H}, \mathrm{CH}=\mathrm{CH}_{2}\right), 6.42(\mathrm{dd}, J=17.3,1.4 \mathrm{~Hz}, 1 \mathrm{H}$, $\mathrm{CH}=\mathrm{CHH}), 7.07(\mathrm{~d}, J=8.6 \mathrm{~Hz}, 1 \mathrm{H}, \mathrm{CH}$ aromatic), $7.9(\mathrm{dd}, J=$ 8.5, $2.0 \mathrm{~Hz}, 1 \mathrm{H}, \mathrm{CH}$ aromatic), 8.03 (d, $J=2.0 \mathrm{~Hz}, 1 \mathrm{H}, \mathrm{CH}$ aromatic). ${ }^{13} \mathrm{C}\left\{{ }^{1} \mathrm{H}\right\} \mathrm{NMR}\left(100 \mathrm{MHz}, \mathrm{CDCl}_{3}, \delta, \mathrm{ppm}\right): 62.43$ (1C, $\mathrm{CH}_{2} \mathrm{O}$ ), 63.00 (1C, $\mathrm{CH}_{2} \mathrm{O}$ ), 116.24 (1C, C aromatic), 120.23 (1C, $\mathrm{C}$ aromatic), 123.29 (1C, $\mathrm{C}$ aromatic), 128.08 (1C, $\mathrm{CH}=\mathrm{CH}_{2}$ ), 130.52 (1C, C aromatic, $\mathrm{CH}$ ), 131.21 (1C, C aromatic), 131.65 (1C, $\mathrm{CH}_{2}=\mathrm{CH}$ ), 155.76 (1C, $\mathrm{C}$ aromatic), $165.13(1 \mathrm{C}, \mathrm{C}=\mathrm{O}$ ), 166.03 (1C, $\mathrm{C}=\mathrm{O})$.

CHB (3). 3.00 g, 11.2 mmol, Yield: 40.7\%. ESI-TOF mass spectrometry: expected $\mathrm{m} / \mathrm{z}$ for $[\mathrm{M}-\mathrm{H}]^{-} 268.04$, found 267.92 Da FT-IR: $\nu$ 3328, 3139, 2938, 2111, 1690, 1646, 1617, 1596, 1527, 1489, 1386, 1357, 1323, 1294, 1265, 1238, 1145, 1118, 1053, 972, 890, 872, 834, 804, $669 \mathrm{~cm}^{-1} \cdot{ }^{1} \mathrm{H}$ NMR $(400 \mathrm{MHz}$, MeOD, $\delta, \mathrm{ppm}): 3.64\left(\mathrm{t}, J=5.4 \mathrm{~Hz}, 2 \mathrm{H}, \mathrm{CH}_{2} \mathrm{~N}\right), 4.36(\mathrm{t}, J=5.4$ $\mathrm{Hz}, 2 \mathrm{H}, \mathrm{OCH}_{2}$ ), $5.66(\mathrm{dd}, 1 \mathrm{H}, J=8.3,3.7 \mathrm{~Hz}, 1 \mathrm{H}, \mathrm{CH}=\mathrm{CHH}$ ), $6.22(\mathrm{dd}, 1 \mathrm{H}, J=17.1,3.7 \mathrm{~Hz}, \mathrm{CH}=\mathrm{CH} H), 6.27(\mathrm{dd}, 1 \mathrm{H}, J=$ $\left.17.1,8.3 \mathrm{~Hz}, \mathrm{CH}=\mathrm{CH}_{2}\right), 6.95(\mathrm{~d}, 1 \mathrm{H}, J=8.5 \mathrm{~Hz}, \mathrm{CH}$ aromatic), 7.82 (m, 1H, CH aromatic), 7.98 (m, 1H, CH aromatic). ${ }^{13} \mathrm{C}$ $\left\{{ }^{1} \mathrm{H}\right\}$ NMR (100 MHz, MeOD, $\delta$ ppm): 39.55 (1C, $\left.\mathrm{CH}_{2} \mathrm{NH}\right), 64.51$ (1C, $\mathrm{CH}_{2} \mathrm{O}$ ), 117.1 (1C, $\mathrm{C}$ aromatic, $\mathrm{CH}$ ), 121.8 (1C, $\mathrm{C}$ aromatic, CCl), 123.18 (1C, C aromatic, CCO), $126.96\left(1 \mathrm{C}, \mathrm{CH}_{2}=\mathrm{C}\right.$ ), 130.95 (1C, $\mathrm{C}$ aromatic, $\mathrm{CH}), 131.83,\left(1 \mathrm{C}, \mathrm{CH}=\mathrm{CH}_{2}\right), 132.79$ (1C, C aromatic, $\mathrm{CH}), 159.16$ (1C, C aromatic, C-OH), 166.83 $(1 \mathrm{C}, \mathrm{C}=\mathrm{O}), 168.45(1 \mathrm{C}, \mathrm{C}=\mathrm{O})$.

\section{General one-pot polymerisation procedure: synthesis of mPEGA $_{12 \mathrm{a}}-b-\mathrm{ACH}_{36}(6)$, block copolymers}

The synthesis of the $\mathrm{pH}$-responsive block copolymers was performed via an adaptation of the one-pot RAFT polymerisation strategy described by Perrier and co-workers. ${ }^{18}$ Monomer conversion after each step are shown in Table 1.

mPEGA $_{12 \mathrm{a}}$ - $\boldsymbol{b}$ - ACH $_{36} \cdot \operatorname{mPEGA}(480)(440 \mu \mathrm{L}, 1.00 \mathrm{mmol})$ and MHP RAFT Agent (19.9 mg, $83.3 \mu \mathrm{mol}$, synthesis and characterisation are reported in the ESI $\dagger$ ) were placed in a tube equipped with a magnetic follower and EtOH $(100 \mu \mathrm{L})$ was added (NOTE: the monomer: solvent vol: vol ratio was found to be critical to achieve the required degree of control over the chain end-group fidelity, in agreement with what described by Perrier and co-workers. ${ }^{18,32-34}$ Here a $2.0 \mathrm{M}$ monomer concentration was used in all cases, and when liquid monomers were used, their volume was taken into account when calculating the solvent required to achieve the required monomer concentration). The tube was sealed with a rubber septum, placed in an ice bath, stirred for $5 \mathrm{~min}$ to allow temperature equilibration, deoxygenated by gentle Argon bubbling for 15 minutes, and finally placed in an oil bath pre-heated at $70{ }^{\circ} \mathrm{C}$. $0.332 \mu \mathrm{mol}$ of VA-044 $\left(59 \mu \mathrm{L}\right.$ of a $1.82 \mathrm{mg} \mathrm{mL}{ }^{-1}$ deoxygenated stock solution in HPLC-grade water) were then added via gas-tight syringe to the reaction tube $\left(t_{0}\right)$. After $2 \mathrm{~h}$ near-quantitative conversion of MPEGA(480) into mPEGA $_{12 a}$ macro-CTA was confirmed by ${ }^{1} \mathrm{H}$ NMR of an aliquot taken from the reaction mixture, which was also analysed by SEC (DMF $+0.1 \%$ $\mathrm{LiBr}$ as the mobile phase) to estimate $M_{\mathrm{n}}$ and polydispersity index of the mPEGA $_{12 a}$ polymer intermediate.

In a separate Schlenk tube ACH monomer (803 mg, $2.96 \mathrm{mmol}$ ) was dissolved in $1.5 \mathrm{~mL}$ of water: EtOH (1:2 vol/ vol); the tube was placed in an ice bath, stirred for 5 min to allow temperature equilibration, and deoxygenated by gentle Argon bubbling for 15 minutes. This solution was then cannu-

Table 1 Characterization and $[\mathrm{M}] /[\mathrm{CTA}] /[\mathrm{l}]$ ratios utilised for the synthesis of $\mathrm{mPEGA}_{12}$ macro-CTAs and $\mathrm{mPEGA}_{12 \mathrm{a}}-b-\mathrm{ACH}_{36}, \mathrm{mPEGA}_{12 b}-b-\mathrm{CHB}_{36}$ block copolymers

\begin{tabular}{|c|c|c|c|c|c|c|}
\hline Polymer & Code & {$[\mathrm{M}] /[\mathrm{CTA}] /[\mathrm{I}]$} & Conv. $\%^{a}$ & $M_{\mathrm{n}, \mathrm{NMR}}(\mathrm{kDa})$ & $M_{\mathrm{n}, \mathrm{SEC}}(\mathrm{kDa})$ & $D$ \\
\hline mPEGA $_{12 b}$ & 5 & $12: 1: 0.004$ & 98 & 5.3 & $6.1^{d}$ & $1.13^{d}$ \\
\hline
\end{tabular}

${ }^{a}$ Obtained from ${ }^{1} \mathrm{H}$ NMR analysis. ${ }^{b}$ Number of repeating unit of $\mathrm{ACH}$ or $\mathrm{CHB}$ monomers, $\mathrm{DP}_{\mathrm{ACH}}$ and $\mathrm{DP}_{\mathrm{CHB}}$ respectively, were calculated by ${ }^{1} \mathrm{H}$ NMR by comparing the integral of monomer aromatic proton peak at $6.93\left(I_{6.93}\right) \mathrm{ppm}$, and the methoxy peak of mPEGA repeating units

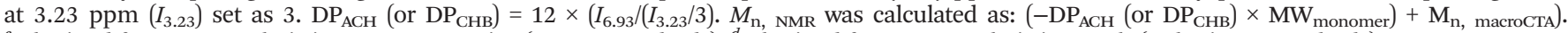
${ }^{c}$ Obtained from SEC analysis in DMF $+0.1 \%$ LiBr (PMMA standards). ${ }^{d}$ Obtained from SEC analysis in $\mathrm{CHCl}_{3}$ (polystirene standards). 
lated under Argon into the polymerisation tube containing mPEG $_{12 a}$ macro-CTA, and the resulting solution heated at $70{ }^{\circ} \mathrm{C}$ under stirring. The polymerisation was started by addition of a previously degassed VA-044 solution in HPLCgrade water $(96 \mu \mathrm{L}, 0.54 \mu \mathrm{mol})$ via gas-tight syringe. After $2 \mathrm{~h}$ at $70{ }^{\circ} \mathbf{C ~ A C H ~ m o n o m e r ~ c o n v e r s i o n ~ w a s ~ c h e c k e d ~ b y ~}{ }^{1} \mathrm{H}$ NMR in DMSO- $\mathrm{d}_{6}$. Three sequential additions of degassed fresh initiator solution $(96 \mu \mathrm{L})$, each followed by $2 \mathrm{~h}$ stirring at $70{ }^{\circ} \mathrm{C}$ were performed, until conversion finally reached $94 \%$.

mPEGA $_{12 \mathbf{b}}-\boldsymbol{b}-\mathbf{C H B}_{36}$ (7). The synthesis of $\mathrm{mPEGA}_{12} \mathrm{~b}-\boldsymbol{b}-\mathrm{CHB}_{36}$ block copolymer was performed as described above, but five sequential additions of degassed VA-044 initiator solution (96 $\mu \mathrm{L}, 0.54 \mu \mathrm{mol}$ ) were performed to reach 99\% monomer conversion.

mPEGA $_{12 a}$ (4). Conversion $=95 \% M_{\mathrm{n}}$, theor $=5.71 \mathrm{kDa}$; $\mathrm{DP}_{\text {theor }}=11.4, M_{\mathrm{n}(\mathrm{GPC}, \mathrm{DMF})}=6.49 \mathrm{kDa} ; \bigoplus_{(\mathrm{GPC}, \mathrm{DMF})}=1.05$.

mPEGA $_{12 b}$ (5). Conversion $=97 \% M_{\mathrm{n}}$, theor $=5.83 \mathrm{kDa}$; $M_{\mathrm{n}\left(\mathrm{GPC}, \mathrm{CHCl}_{3}\right)}=5.3 \mathrm{kDa} ; \mathrm{DP}=11.6 ; \bigoplus_{\left(\mathrm{GPC}, \mathrm{CHCl}_{3}\right)}=1.13$.

mPEGA $_{12 \mathrm{a}}-\boldsymbol{b}-\mathrm{ACH}_{36}$ (6). Conversion $=94 \% ; M_{\mathrm{n}}$, theor $=$ $14.92 \mathrm{kDa} ; M_{\mathrm{n}}(\mathrm{GPC}, \mathrm{DMF})=14.9 \mathrm{kDa} ; \mathrm{DP} 2^{\text {nd }}$ block $=36$; $\bigoplus_{(\mathrm{GPC}, \mathrm{DMF})}=1.18$.

mPEGA $_{12 b}-\boldsymbol{b}-\mathbf{C H B}_{36}$ (7). Conversion $=99 \% ; M_{\mathrm{n}}$, theor $=$ $14.97 \mathrm{kDa} ; M_{\mathrm{n}}(\mathrm{GPC}, \mathrm{DMF})=15.07 \mathrm{kDa} ; \mathrm{DP}_{\text {theor }} 2^{\text {nd }}$ block $=36$; $\bigoplus_{(\mathrm{GPC}, \mathrm{DMF})}=1.17$.

\section{In line assembly of polymersomes}

In a typical procedure, at the end of the polymerisation run the reaction mixture was diluted with EtOH to a final polymer concentration of $35 \mathrm{mg} \mathrm{mL}{ }^{-1}$ while maintaining the temperature at $40{ }^{\circ} \mathrm{C}$, under stirring. The resulting polymer solution was then directly cannulated into DI water $\left(\mathrm{EtOH}: \mathrm{H}_{2} \mathrm{O} 1: 35\right.$ $\mathrm{vol} / \mathrm{vol}$, final polymer concentration $1.0 \mathrm{mg} \mathrm{mL}^{-1}$ ).

The polymersomes formation occurred instantaneously, as confirmed by DLS. To remove the residual ethanol, the vesicles suspension was transferred into a dialysis bag (3.5 kDa MWCO) and dialyzed against 5 L of DI water for 4 hours at room temperature with at least 4 water exchanges. Alternatively, the beaker containing the polymersomes suspensions were left to stir overnight to allow the organic solvent to evaporate. Samples were analysed by DLS and TEM.

\section{Polymersomes assembly by nanoprecipitation}

For comparative purposes, assembly of polymersomes was also performed by nanoprecipitation on purified block copolymers. Briefly, at the end of the polymerisation reaction mixtures were diluted with acetone $(10 \mathrm{~mL})$ and precipitated twice in petroleum ether $(200 \mathrm{~mL}) .5 \mathrm{mg} \mathrm{mL}{ }^{-1}$ polymer solutions were then prepared in DMSO, and diluted to $1 \mathrm{mg} \mathrm{mL}^{-1}$ by addition of either water or PBS. To remove the organic solvent, vesicles suspensions were transferred into a dialysis bag $3.5 \mathrm{kDa}$ MWCO) and dialyzed against 5 L of DI water or PBS for 24 hours at room temperature with at least 4 solvent exchanges. Vesicles size was analysed by DLS and, for samples prepared in PBS, by atomic force microscopy (AFM).

\section{Polymersome assembly via a microfluidic device}

Polymersomes were also assembled using a bespoke microfluidic device. Two syringes feeding into the device were driven simultaneously by a dual Cole-Palmer 789210C syringe pump. A $10 \mathrm{~mL}$ syringe (internal diameter $15.8 \mathrm{~mm}$ ) delivered at 12 times the volume flow rate of the $1 \mathrm{~mL}$ syringe (internal diameter $4.6 \mathrm{~mm}$ ). The $1 \mathrm{~mL}$ syringe was maintained at $50{ }^{\circ} \mathrm{C}$ by a heating jacket and contained an ethanolic solution $(12 \mathrm{mg}$ $\mathrm{mL}^{-1}$ ) of $\mathrm{mPEGA}_{12 \mathrm{~b}}-b-\mathrm{CHB}_{36}$. This solution was injected into the device at a flow rate of $10 \mu \mathrm{L} \mathrm{min}{ }^{-1}$ (Flow A, Fig. 4), via a $27 \mathrm{G}$ needle (internal diameter $0.21 \mathrm{~mm}$ ) inserted into a PTFE tube (ID $0.5 \mathrm{~mm}$ ). The tube ensured a leak-free fit while allowing the needle to be removed as required. Concurrently, water was introduced in the device via the $10 \mathrm{~mL}$ syringe, through another ID $0.5 \mathrm{~mm}$ PTFE tube, at a flow rate of $120 \mu \mathrm{L} \mathrm{min}{ }^{-1}$ (Flow B, Fig. 4). The tubes led to a mixing junction placed on a $60{ }^{\circ} \mathrm{C}$ hotplate, and the mixed flow (Flow C, $130 \mu \mathrm{L} \mathrm{min}{ }^{-1}$, Fig. 4) excited the device to a collection vial via an ID $1 \mathrm{~mm}$ tube. The experiment was repeated twice and at least 3 different samples were collected and analysed by DLS.

\section{Drug loading procedure}

Terbinafine free base and cyanocobalamin co-loaded polymersomes were assembled following a procedure analogous to that described in the "in line assembly of polymersomes" section. Typically, terbinafine free base $(10 \% \mathrm{w} / \mathrm{w}$ drug/ polymer) and cyanocobalamin $(10 \% \mathrm{w} / \mathrm{w}$ drug/polymer) were respectively added to the polymer ethanolic/water solution and/or the aqueous phase before the assembly procedure. To remove unentrapped cyanocobalamin and residual organic solvent the polymersomes suspension was dialysed with $8 \mathrm{kDa}$ MWCO dialysis membrane against 5 L of DI water, with 4 water exchanges in 5 hours. Unentrapped terbinafine, precipitated after dialysis, was removed by centrifugation $(1500 \mathrm{rpm}$, 5 minutes) followed by filtration through a $0.45 \mu \mathrm{m}$ mixed cellulose ester membrane.

Drug loading was then quantified via a RP-HPLC method (see $\mathrm{ESI}^{\dagger}$ ). Loading reported for each polymer is the average of two independent experiments, each prepared and analysed in triplicate.

Loading Capacity (LC) and Encapsulation Efficiency (EE) were calculated as:

$$
\begin{aligned}
& \mathrm{LC}=\frac{\text { Amount of loaded drug }}{\text { Amount of polymer }} \times 100 \\
& \mathrm{EE}=\frac{\text { Amount of loaded drug }}{\text { Total amount of drug }} \times 100
\end{aligned}
$$

\section{Polymersome size analysis}

Particles size analyses were carried out at $25^{\circ} \mathrm{C}$ by Dynamic Light Scattering (DLS) using a Zetasizer Nano spectrometer (Malvern Instruments Ltd) equipped with a $633 \mathrm{~nm}$ laser at a fixed angle of $173^{\circ}$. Samples were kept at constant temperature $\left(25^{\circ} \mathrm{C}\right)$ during all the experiments. Polymeric vesicles were prepared as described in "in line assembly of polymersomes", by 
nanoprecipitation or via microfluidic device. Residual EtOH was removed either by solvent evaporation or by dialysis with a $3.5 \mathrm{kDa}$ MWCO dialysis membrane before analysis. Results are reported as the $z$-average. All experiments were performed in triplicate.

\section{Transmission electron microscopy (TEM)}

Transmission Electron Microscopy (TEM) was performed on a FEI TecnaiTM 12 Biotwin transmission electron microscope. $20 \mu \mathrm{L}$ of $1 \mathrm{mg} \mathrm{mL} \mathrm{m}^{-1}$ polymersomes suspension in water were placed on a carbon coated copper grid. After 5 minutes the excess of volume was wicked away with filter paper, the samples were negatively stained with $3 \%$ uranyl acetate in distilled water and analysed. 191 and 207 individual vesicles were measured from the digitised images for mPEGA $_{12 \mathrm{a}}-b-\mathrm{ACH}_{36}$ and $\mathrm{mPEGA}_{12 \mathrm{~b}}-b-\mathrm{CHB}_{36}$, using image 1.45 analysis software.

\section{Atomic force microscopy (AFM)}

Atomic Force Microscopy topography images of mPEGA $_{12 a}-b$ $\mathrm{ACH}_{36}$ and $\mathrm{mPEGA}_{12 \mathrm{a}}-b-\mathrm{CHB}_{36}$ polymersomes were obtained in liquid at room temperature using a Bruker Icon FastScan Bio operating in PeakForce nanomechanical tapping mode in fluid using ScanA-syst-Fluid + probes (resonant mechanical frequency: 120-180 kHz, spring constant: $0.7 \mathrm{~N} \mathrm{~m}^{-1}$ ). Images were acquired under ScanAsyst auto control using scan rates of $1.60 \mathrm{~Hz}$, with a resolution of $512 \times 512$ pixels. Small pieces $(0.5 \mathrm{~cm} \times 0.5 \mathrm{~cm})$ of freshly cleaved mica were used as substrates. $10 \mathrm{mM} \mathrm{MgCl}_{2}$ solution was incubated with cleaved mica for $30 \mathrm{~min}$. Subsequently, the mica was washed with distilled water and blow-dried under nitrogen stream at room temperature. Polymersomes prepared by the nanoprecipitation method followed by dialysis against PBS were diluted with additional PBS to a final polymer concentration of $500 \mu \mathrm{g} \mathrm{mL}$ and filtered through a $0.45 \mu \mathrm{m}$ syringe filter. The diluted polymersome solution $(100 \mu \mathrm{L})$ was pipetted on the mica substrate and then imaged. Image data were analysed using Nanoscope Analysis software (Version 1.5, Bruker).

\section{Results and discussion}

\section{In line polymersomes: synthesis of $\mathrm{ACH}$ acrylate and $\mathrm{CHB}$ acrylamide-based copolymers mPEGA $\mathrm{A}_{12 \mathrm{a}}-\mathrm{b}-\mathrm{ACH}_{36}$ and mPEGA $_{12 b}-b-C_{36}$}

Accordingly, in this work the required monomers were prepared in one step, by DCC-mediated coupling reaction of 3-chloro-4-hydroxybenzoic acid with (hydroxyethyl)acrylate (HEA) or (hydroxyethyl)acrylamide (HEAM), to give acrylate and acrylamide monomers ACH (2) and CHB (3), respectively (Scheme 1, and ESI, Fig. S5-S8†). Unlike our previous studies where methacrylates were utilised, ${ }^{35,36}$ in this work the analogous acrylate/acrylamide monomers, characterised by higher propagation rate coefficient $\left(K_{\mathrm{p}}\right),{ }^{37,38}$ required for subsequent one-pot rapid multiple chain extensions at close to full monomer conversion, as described by Perrier and co-workers, were synthesised. To prove the versatility of the strategy developed in this study, both acrylate and acrylamide monomers were utilised.

To successfully prepare multiblock copolymers via this onepot RAFT process, a number of parameters - e.g. choice of the solvent, initiator, monomer concentration, temperature and $[\mathrm{CTA}] /[\mathrm{I}]$ ratio - are key for maintaining near-perfect chain-end fidelity, thus ensuring "livingness" of the polymerisation. ${ }^{18}$

A mixture of water/EtOH was chosen as a suitable "green" solvent ${ }^{39}$ for the subsequent polymerisation step. Water is known to increase the propagation rate coefficient $\left(K_{\mathrm{p}}\right)$, and

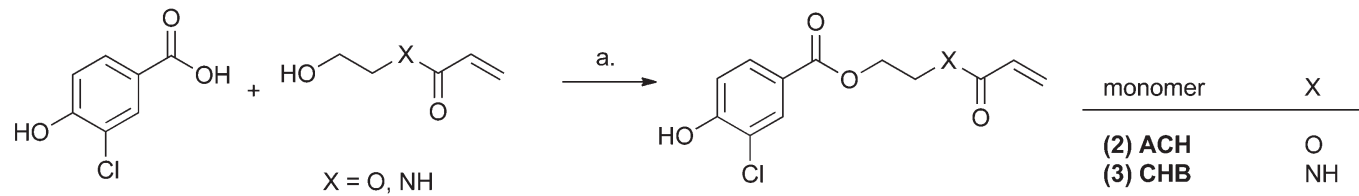

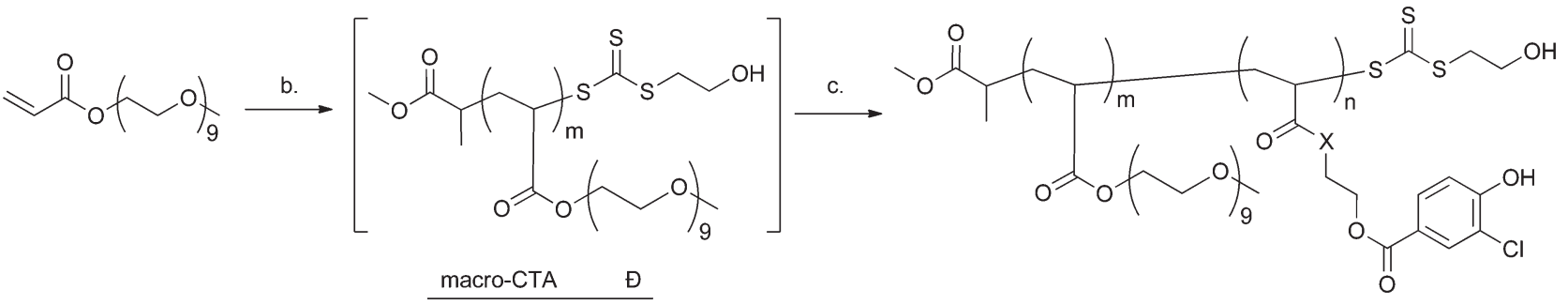

\begin{tabular}{ll} 
& \\
\hline (4) mPEGA $_{12 a}$ & 1.05 \\
(5) mPEGA $_{12 b}$ & 1.13
\end{tabular}

\begin{tabular}{lcccc} 
copolymer & $X$ & $\mathrm{~m}$ & $\mathrm{n}$ & $Ð$ \\
\hline (6) mPEGA $_{12 \mathrm{a}}-\boldsymbol{b}-\mathrm{ACH}_{36}$ & $\mathrm{O}$ & 12 & 36 & 1.18 \\
(7) mPEGA $_{12 \mathrm{~b}}-\boldsymbol{b}-\mathrm{CHB}_{36}$ & $\mathrm{NH}$ & 12 & 36 & 1.05
\end{tabular}

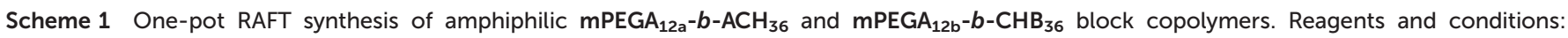

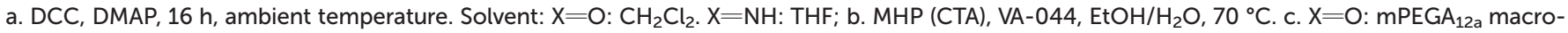
$\mathrm{CTA}, \mathrm{ACH}$ monomer, VA-044, EtOH$/ \mathrm{H}_{2} \mathrm{O}, 70{ }^{\circ} \mathrm{C} ; \mathrm{X}=\mathrm{NH}$ : $\mathrm{mPEGA}_{12 \mathrm{~b}}$ macro-CTA, $\mathrm{CHB}$ monomer, VA-044, EtOH/H $\mathrm{O}_{2}, 70{ }^{\circ} \mathrm{C}$. 
thus the polymerisation rate $\left(R_{\mathrm{p}}\right)$, of vinyl monomers, ${ }^{40}$ which is critical for efficient in situ RAFT synthesis of multiblock copolymers, ${ }^{18}$ whilst EtOH was required to solubilise the monomers ACH (2) and CHB (3), and the (methyl 2-((((2hydroxyethyl)thio)carbonothioyl)thio)propanoate), (MHP) chaintransfer agent. The latter was chosen due to the higher hydrolytic stability of trithiocarbonates compared to other suitable CTAs - e.g. dithioesters - and their ability to minimise initial rate retardation sometimes observed in RAFT polymerisations. ${ }^{41}$ In the one-pot protocol optimised in this work a macro-CTA was first synthetised using commercially available poly[ethylene glycol(480)]methyl ether acrylate, mPEGA(480) and 2,2'-azobis[2-(2-imidazolin-2-yl)propane]dihydrochloride (VA-044) as the water soluble initiator [I], at $70{ }^{\circ} \mathrm{C}$ (Scheme 1). VA-044 is characterised by a high decomposition rate $\left(t_{1 / 2} 2 \mathrm{~h}\right.$ at $70^{\circ} \mathrm{C}$ ), which again is key to speeding up the polymerisation without losing the chain livingness. ${ }^{32,33} \operatorname{mPEGA(480)}$ was chosen for the synthesis of the first hydrophilic block because of its aqueous solubility, biocompatibility and ability to generate polymers with prolonged plasma half-life and low immunogenicity. ${ }^{42-44}$ After an initial series of experiments required to identify suitable reaction conditions (i.e. monomer concentration and $[\mathrm{CTA}] /[\mathrm{I}]$ molar ratio) which would allow to reach near-quantitative monomer conversion whilst retaining chain-end fidelity, a [CTA]/[I] ratio of $250: 1$ and a monomer concentration of $2.0 \mathrm{M}$ were chosen. The degree of polymerisation (DP) for the p(mPEGA) macro-CTA was targeted to 12 . After $2 \mathrm{~h}$ the reaction reached a monomer conversion $>95 \%$, as assessed by ${ }^{1} \mathrm{H}$ NMR, by comparing the decrease of the signal for the vinyl proton at $\sim 5.96 \mathrm{ppm}$ to that of the MPEG terminal methoxy group at $3.24 \mathrm{ppm}$ (see ESI, Fig. S9 and S10†). SEC analysis of the macro-CTA $\left(\mathrm{mPEG}_{12 \mathrm{a}}, \mathrm{mPEG}_{12 \mathrm{~b}}\right.$, Table 1 and Fig. 1), using DMF $+0.1 \% \mathrm{LiBr}$ as the mobile phase showed unimodal, symmetric, and narrow molecular weight distributions $(\nexists<1.13)$, with $M_{\mathrm{n}}$, sEC in good agreement with the theoretical one (Table 1, polymers 4 and 5). Two different macro-CTAs, mPEGA $_{12 \mathrm{a}}$ and mPEG $_{12 \mathrm{~b}}$, both with DP $=12$ were synthesised and directly utilised without isolation or purifi-

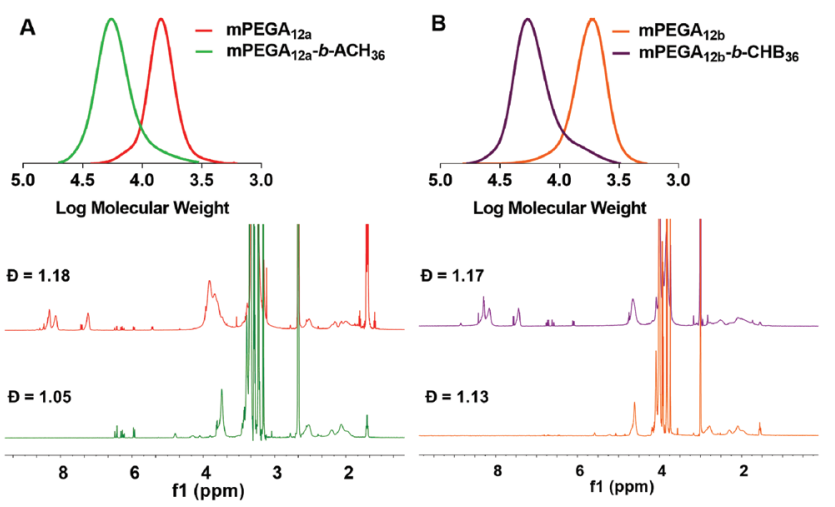

Fig. 1 SEC traces and ${ }^{1} \mathrm{H}$ NMR spectra $\left(D M S O-d_{6}\right)$ of non-purified $\mathrm{mPEGA}_{12}$ macro-CTA and final block copolymers for A. mPEGA ${ }_{12 a}-b$ $\mathrm{ACH}_{36}(6)$, and B. mPEGA ${ }_{12 b}-b-\mathrm{CHB}_{36}$ (7). cation for the synthesis of $\mathrm{mPEGA}_{12 \mathrm{a}}-b-\mathrm{ACH}_{36}$ (6) and mPEGA $_{12 \mathrm{~b}}-b-\mathrm{CHB}_{36}$ (7), respectively. Importantly, both reactions led to the desired mPEGA $_{12}$ macro-CTAs with near-quantitative monomer conversion, thus validating the reproducibility of this process. Both acrylate ACH (2) and acrylamide CHB (3) monomers have limited solubility in water, hence for the second polymerisation step they were first dissolved in $\mathrm{EtOH}$, then the resulting solutions were diluted with water to a final EtOH/water volume ratio of $2: 1$. To ensure full monomer conversion in the one-pot RAFT with higher EtOH content, a larger amount of radical intitiator was required; ${ }^{33}$ in this work for the second block a [macro-CTA]/[I] ratio of 150:1 was initially chosen in both cases. A DP of 34 for both ACH and CHB was targeted, to provide final copolymers with a hydrophilic block weight fraction $(f=35 \% \pm 10 \%)^{45}$ suitable for selfassembling into vesicles. ${ }^{2}$ Indeed, when considering the $M_{\mathrm{n}}$ provided by ${ }^{1} \mathrm{H}$ NMR analysis the calculated $f$ values were 0.358 and 0.357 for mPEGA $_{12 \mathrm{a}}-b-\mathrm{ACH}_{36}$ and $\mathrm{mPEGA}_{12 \mathrm{~b}}-b-\mathrm{CHB}_{36}$, respectively.

Following the addition of ACH (2) or CHB (3) monomers and VA-044 radical initiator, a monomer conversion of $80-90 \%$ was observed after 2 hours. Additional radical initiator was necessary to achieve $>95 \%$ of monomer conversion (Table 1 , polymer 6 and 7, see ESI Fig. S11 and S12†), resulting in a final [macro-CTA]/[I] ratio of $1: 50$ or $1: 30$ for $\operatorname{mPEGA}_{12 \mathrm{a}}-b$ $\mathrm{ACH}_{36}$ and $\mathrm{mPEGA}_{12 \mathrm{~b}}-b-\mathrm{CHB}_{36}$, respectively. A possible explanation for this is that the second block grown here is longer than most of those prepared by Perrier and coworkers for which near-full conversion could be achieved under the conditions reported, ${ }^{18,27,32-34}$ although other side-processes - e.g. very minimal $\mathrm{H}$ transfer from ACH (2) or CHB (3) monomers cannot in theory be ruled out at this stage. Nevertheless, pleasingly, SEC analysis (Table 1 and Fig. 1) showed that very well defined block-copolymers with a final $D$ of $1.18\left(\right.$ mPEGA $_{12 \mathrm{a}}-b$ $\left.\mathrm{ACH}_{36}\right)$ and $1.17\left(\mathrm{mPEGA}_{12 \mathrm{~b}}-b-\mathrm{CHB}_{36}\right)$, were synthesised indicating good control over the polymerisation process. The DP of the second block was determined by ${ }^{1} \mathrm{H}$ NMR, by comparing the integral of the $\mathrm{OCH}_{3}$ signal of mPEGA repeating units in the hydrophilic block at $3.24 \mathrm{ppm}$, with that of the aromatic proton of $\mathrm{ACH}$ and $\mathrm{CHB}$ repeating units at $6.93 \mathrm{ppm}$ (ESI, Fig. S11 and $\mathrm{S} 12 \dagger)$. A $\mathrm{DP}_{\mathrm{NMR}}$ of 36 was found for the second block of both mPEGA $12 \mathrm{a}-b-\mathrm{ACH}_{36}$ (6), and mPEGA $_{12 \mathrm{~b}}-b-\mathrm{CHB}_{36}$ (7), slightly higher than the expected 34 . This can be explained considering that a minimal amount of MPEGA $_{12}$ macro-CTA was withdrawn at the end of the first polymerisation step for ${ }^{1} \mathrm{H}$ NMR and SEC analysis, thus very marginally increasing the monomer : macro-CTA molar ratio.

\section{Polymersomes in-line assembly, drug loading and characterization}

At the end of the polymerisation runs the reaction mixtures were diluted with additional EtOH to a polymer concentration of $35 \mathrm{mg} \mathrm{mL} \mathrm{m}^{-1}$ (total volume $37 \mathrm{~mL}$ ) to facilitate the subsequent manipulations and assembly of $\mathrm{mPEGA}_{12 \mathrm{a}}-b-\mathrm{ACH}_{36}$ (6) and $\mathrm{mPEGA}_{12 \mathrm{~b}}-b-\mathrm{CHB}_{36}$ (7) into their corresponding polymersomes. The resulting solutions were kept at $40{ }^{\circ} \mathrm{C}$ to ensure 
full polymer solubilisation and reduced viscosity of the polymer solutions. To assemble non drug-loaded vesicles these solutions were directly cannulated under stirring into DI water (final polymer concentration of $1 \mathrm{mg} \mathrm{mL}^{-1}$ ).

Polymersomes assembly was confirmed by DLS analysis of the water/ethanol mixture immediately after the cannulation process. DLS traces showed the presence of nanoassemblies with an average diameter of $136 \pm 2 \mathrm{~nm}$ and $89 \pm 11 \mathrm{~nm}$ for mPEGA $_{12 \mathrm{a}}-b-\mathrm{ACH}_{36}$, and $\mathrm{mPEGA}_{12 \mathrm{~b}}-b-\mathrm{CHB}_{36}$, respectively.

Ethanol was removed by either dialysis or slow evaporation at room temperature, and the resulting assemblies were characterised by dynamic light scattering (DLS) and transmission electron microscopy (TEM). The in line polymersomes assembly process led to homogeneous dispersions of polymeric vesicles in water, (Fig. 2A), with hydrodynamic diameters estimated by DLS of $122 \pm 20 \mathrm{~nm}$ or $41 \pm 0.18 \mathrm{~nm}$, for $\mathrm{mPEGA}_{12 \mathrm{a}}-b-\mathrm{ACH}_{36}$ (6) and $\mathrm{mPEGA}_{12 \mathrm{~b}}-b-\mathrm{CHB}_{36}$ (7), respectively, with narrow PDI $(<0.23)$. Similar results in terms of vesicle size and polydispersity were obtained regardless of the method used for removal of traces of ethanol in the polymersomes suspension (data not shown).

To test the efficiency of the in-line process in assembling well-defined vesicles, conventional nanoprecipitation of purified mPEGA $_{12 \mathrm{a}}-b-\mathrm{ACH}_{36}$ (6) and $\mathrm{mPEGA}_{12 \mathrm{~b}}-b-\mathrm{CHB}_{36}$ (7) was also performed. Accordingly, polymers were dissolved in DMSO $(5.0 \mathrm{mg}$ $\mathrm{mL}^{-1}$ ) and water was added dropwise to the resulting solution until a $1.0 \mathrm{mg} \mathrm{mL}^{-1}$ concentration was reached.

This procedure led to the formation of very similar size vesicles in the case of $\mathrm{mPEGA}_{12 \mathrm{a}}-b-\mathrm{ACH}_{36}(122 \pm 9 \mathrm{~nm})$, but larger assemblies in the case of MPEGA $_{12 \mathrm{~b}}-b-\mathrm{CHB}_{36}(172 \pm 2 \mathrm{~nm}$ ESI, Fig. S13 $\dagger$ ), a difference that could be ascribed to the different procedures and conditions used for their assembly. ${ }^{46}$
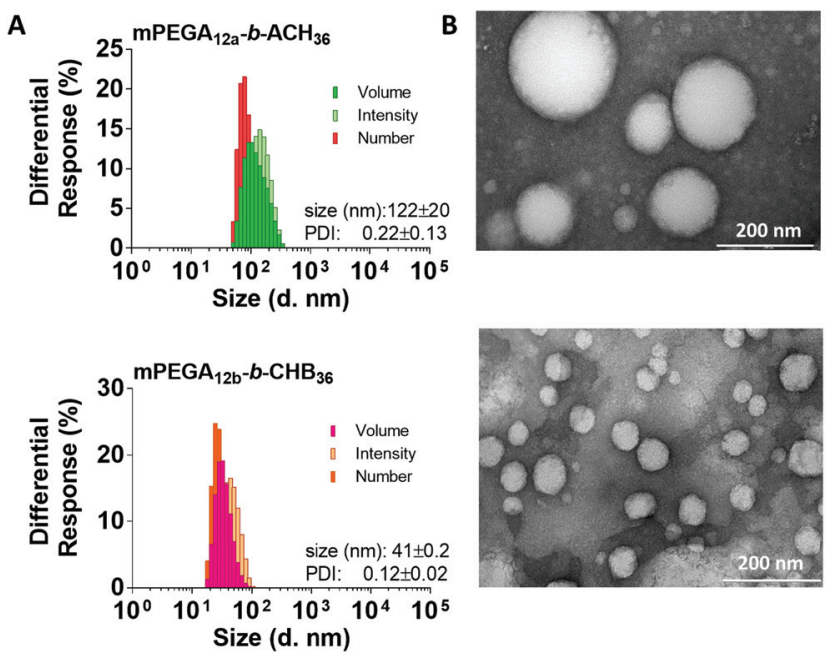

Fig. 2 Characterisation of in-line assembled $\mathrm{mPEGA}_{12 \mathrm{a}}-b-\mathrm{ACH}_{36}$ and $\mathrm{mPEGA}_{12 \mathrm{~b}}-b-\mathrm{CHB}_{36}$ polymersomes (A) DLS analysis of one representative sample. Size shown refers to distribution of hydrodynamic diameter measured by DLS at $173^{\circ}$ in water, at $25^{\circ} \mathrm{C}$. Size $(\mathrm{nm})$ is reported as $z$-average mean. $N=2$. (B) TEM images of polymersomes stained with $3 \%$ uranyl acetate solution.
Analysis of the TEM images performed (ESI Fig. S14 and $\mathrm{S} 15 \dagger$ ) on polymersomes prepared via the in-line procedure and stained with $3 \%$ uranyl acetate solution gave results consistent with the size estimated by DLS for both MPEGA $_{12 \mathrm{a}}-b-\mathrm{ACH}_{36}$, with an average core diameter of $126 \pm 75 \mathrm{~nm}$, and PPEGA $_{12 b^{-}}$ $b$ - $\mathrm{CHB}_{36}(44 \pm 5 \mathrm{~nm})$.

To gain further insight into the morphology of these vesicles in solution, mPEGA $_{12 \mathrm{a}}-b-\mathrm{ACH}_{36}$ and mPEGA $_{12 \mathrm{a}}-b-\mathrm{CHB}_{36}$ polymersomes were analysed by AFM in PeakForce tapping mode (Fig. 3). A major advantage of this method is that the sample can be imaged in solution, thus obtaining a more realistic representation of the vesicles morphology in comparison to microscopy techniques performed on dry samples (i.e. TEM). Furthermore, the use of tapping instead of contact mode avoid the flattening caused by the pressure exterted, allowing a more accurate estimation of vesicle size and threedimensional shape.

Immobilisation of the polymersomes on the mica surface, a pre-requisite to perform the analysis, was achieved by electrostatic interactions. ${ }^{47}$ As described by $\mathrm{Li}$ et al. ${ }^{48}$ negatively charged polymers can be easily immobilized on a mica
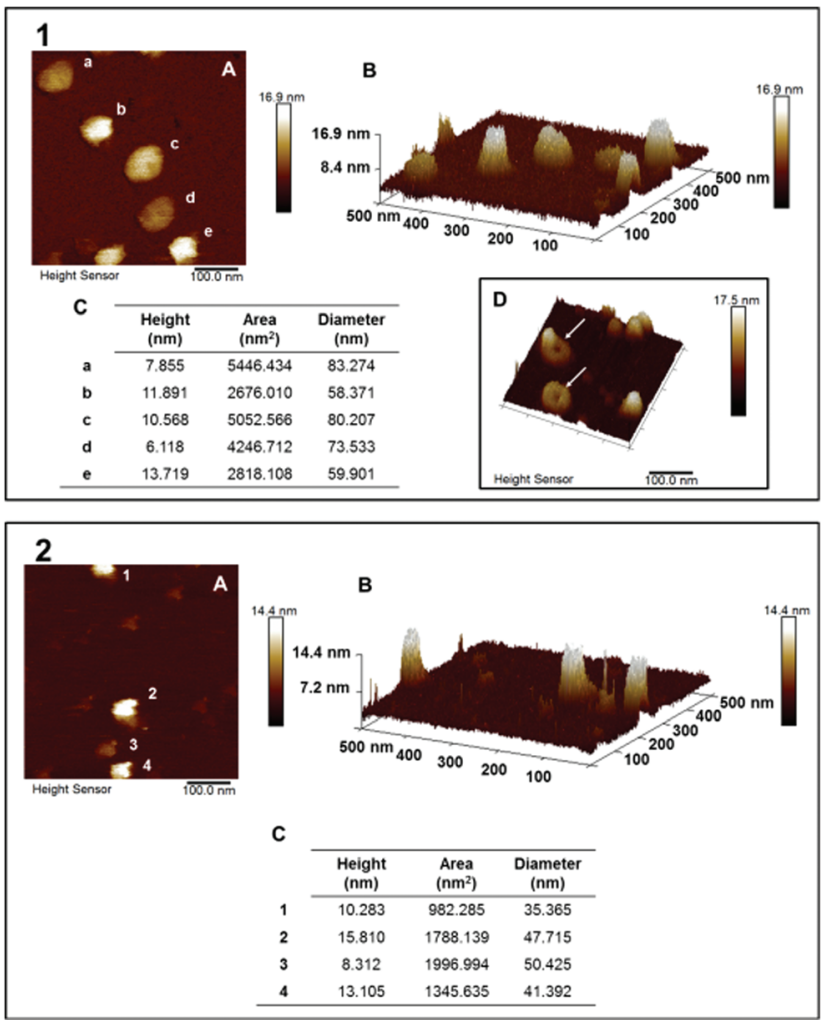

Fig. 3 Representative examples of vesicle morphology as seen by AFM analysis of polymersomes prepared from 1. $\mathrm{mPEGA}_{12 a}-b-\mathrm{ACH}_{36}$ and 2. $\mathrm{mPEGA}_{12 a}-b-\mathrm{CHB}_{36}$. A. AFM height image of polymersomes adsorbed on a mica surface in PBS solution $\left(0.50 \mathrm{mg} \mathrm{mL}^{-1}\right)$; $\mathrm{B}$. The corresponding topographic 3D rendered image showing the distribution of polymersome heights; $C$. List of the mean height, mean area and mean diameter of adsorbed polymersomes at positions a-e or 1-4. D. Arrows highlight some of the collapsed vesicle structures observed during these measurements. 
surface, also negatively charged, via electrostatic interaction mediated by $\mathrm{Mg}^{2+}$.

Our previous studies ${ }^{35}$ showed that at physiological conditions ( $\mathrm{pH}$ 7.4) polymers containing 3-chloro-4-hydroxybenzoate repeating units are negatively charged due to the deprotonation of part of their aromatic alcohol pendant groups. Accordingly, $1.0 \mathrm{mg} \mathrm{mL}^{-1}$ polymersome suspensions were prepared by nanoprecipitation in PBS buffer. The average sizes detected were around $80 \mathrm{~nm}$ for $\mathrm{mPEGA}_{12 \mathrm{a}}-b-\mathrm{ACH}_{36}$ and $45 \mathrm{~nm}$ for $\mathrm{mPEGA}_{12 \mathrm{a}}-b-\mathrm{CHB}_{36}$ (Fig. 3). The height of both polymeric aggregates was found to be around 14-17 nm, thus smaller than their diameter, which can be ascribed to a partial collapse of their hollow structure, thus confirming their vesicular morphology. ${ }^{49}$ Partially collapsed structures with typical 'deflated' balloon' morphology could also be visualized (Fig. 3, insert 1D), thus further confirming the vesicular nature of these supramolecular assemblies.

Larger sizes were estimated by DLS analysis of the polymersomes in PBS (170 and $70 \mathrm{~nm}$ for $\mathrm{mPEGA}_{12 \mathrm{a}}-b-\mathrm{ACH}_{36}$ and mPEGA $_{12 \mathrm{a}}-b-\mathrm{CHB}_{36}$, respectively, Fig. S16 ESI $\dagger$ ) in comparison to those observed by AFM analysis. It has already been shown that the vesicles hydrodynamic diameter estimated by DLS can be larger than the geometrical diameter because of the hydration layer of the polymer shell. ${ }^{50}$ Liang et al. have discussed a similar discrepancy observed when analysing EggPC/ cholesterol vesicles by both DLS and AFM and ascribed it to a potential partial fragmentation of larger vesicle upon adsorption on mica, and/or the intrinsic higher sensitivity of DLS for larger vesicle, which results in an overestimation of the mean hydrodynamic diameter. ${ }^{51}$ The latter phenomenon has also been described when $\mathrm{AgNPs}^{53}$ and polystyrene nanoparticles ${ }^{52}$ were utilised to compare these two analytical techniques.

To establish an automated and robust process to generate polymersomes reproducibly and with very low polydispersity, a microfluidic system was then engineered (Fig. 4). Indeed, microfluidic strategies have been successfully employed to fabricate soft micro- and nano-assemblies ${ }^{54,55}$ To this aim, polytetrafluoroethylene (PTFE) tubing were secured with gaskets inside the screw-tight caps of a 3-way connector. An ethanolic solution $\left(12 \mathrm{mg} \mathrm{mL}^{-1}\right)$ of $\mathrm{mPEGA}_{12 \mathrm{~b}}-b-\mathrm{CHB}_{36}$ maintained at $50{ }^{\circ} \mathrm{C}$ was injected via pump syringe at $10 \mu \mathrm{L} \mathrm{min}^{-1}$ (Flow A, Fig. 4) into a junction where DI water entered via

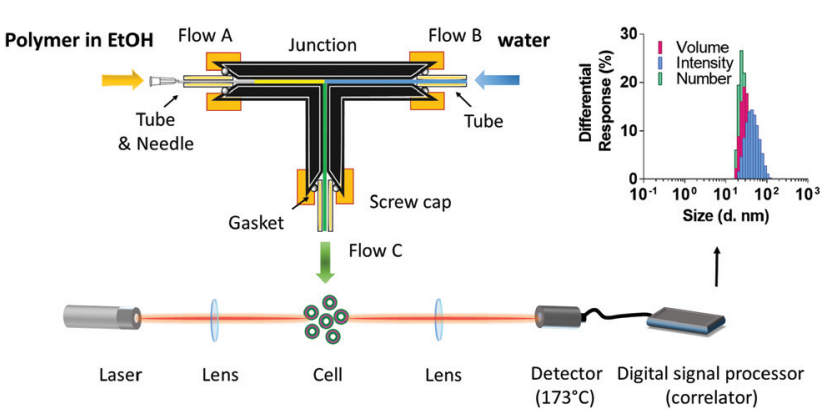

Fig. 4 Automated assembly of $\mathrm{mPEGA}_{12 \mathrm{~b}}-b-\mathrm{CHB}_{36}$ polymersomes: schematic representation of the microfluidic device utilised in this study. another ID $0.5 \mathrm{~mm}$ tube at a flow rate of $120 \mu \mathrm{L} \mathrm{min}^{-1}$ (Flow B, Fig. 4). The mixed liquids (Flow C, Fig. 4) exited the junction via an ID $1 \mathrm{~mm}$ tube and were collected for size analysis. A range of A and B flow rates were tested in preliminary experiments to optimize the solvent mixing inside the connector. Polymersomes were obtained with this methodology at a rate of $0.12 \mathrm{mg} \mathrm{min}{ }^{-1}$, and were analysed by DLS before and after ethanol evaporation.

The average size in the two cases was found to be very similar, with a diameter for the vesicles in pure water of $37 \pm$ $7 \mathrm{~nm}$ and a PDI of $0.15 \pm 0.04$. One of the major advantages offered by this technique is the possibility of finely tuning the ratio of the two solvents in the device by independently modifying the solvent flow rates via syringe pumps, and to minimise the use of organic solvent required to induce the formation of homogeneous vesicles. The accurate control of the flow rate also resulted in very consistent batch to batch reproducibility (Fig. S17 ESI $\dagger$ ), in a process that could easily be scaled up for large scale production.

Finally, the efficiency of the in-line assembly process to incorporate hydrophilic and hydrophobic drugs within the vesicle structures was then investigated. In general, therapeutics are entrapped within polymersomes either during their preparation, or by introduction of drug molecules into pre-formed vesicles. ${ }^{21}$ For the latter, injection ${ }^{56}$ or electroporation $^{57}$ techniques are typically employed. In the former case, hydrophobic molecules can be incorporated into polymeric films utilised to prepare polymersomes, whilst hydrophilic drugs can be introduced into the aqueous phase used to rehydrate these films. ${ }^{58}$ Other commonly used techniques include solvent exchange mediated encapsulation, ${ }^{59}$ and the use of microfluidics to load small molecules or proteins while forming vesicles. ${ }^{60}$

In this present study two model molecules, terbinafine, a hydrophobic antifungal drug which is very poorly soluble in water in its free base form $\left(<2 \mu \mathrm{g} \mathrm{mL}^{-1}\right.$, as assessed by RP-HPLC, data not shown), and hydrophilic cyanocobalamine (Vit B12, solubility in water $\left.c a .10-11 \mathrm{mg} \mathrm{mL}^{-1}\right)^{61}$ were chosen as model drugs for incorporation within vesicle lipophilic membrane and aqueous lumen, respectively. In addition to its hydrophobic nature, terbinafine was chosen due to the presence of a tertiary alkyl amine in its structure, which by forming ionic pairs with the weakly acidic 3-chloro-4-hydroxybenzoic ester repeating units $\left(\mathrm{p} K_{\mathrm{a}} 7-7.5\right)^{36}$ in the hydrophobic blocks of $\mathrm{mPEGA}_{12 \mathrm{a}}-b-\mathrm{ACH}_{36}$ and $\mathrm{mPEGA}_{12 \mathrm{~b}}-b-\mathrm{CHB}_{36}$ could lead to more efficient drug entrapment. This phenomenon was observed in our previous studies using analogous block copolymers, where we utilised tamoxifen, a hydrophobic drug with a basic tertiary amine group, which gave drug loading capacity as high as $18 \% .{ }^{36}$ In typical experiments, at the end of the polymerisation reaction an ethanolic solution of terbinafine free base ( $35 \mathrm{mg} \mathrm{mL}^{-1}$ ) was added via syringe to the polymerisation mixture to give a $10 \% \mathrm{w} / \mathrm{w}$ drug/polymer solution, at $40{ }^{\circ} \mathrm{C}$. Cyanocobalamine was dissolved in the aqueous medium used for the subsequent assembly of $\mathrm{mPEGA}_{12 \mathrm{a}^{-}}$ $b$ - $\mathrm{ACH}_{36}$ (6) and $\mathrm{mPEGA}_{12 \mathrm{~b}}-b$ - $\mathrm{CHB}_{36}$ (7)-based polymersomes, 
again in a $10 \% \mathrm{w} / \mathrm{w}$ drug/polymer ratio. The polymer-terbinafine solutions were then cannulated into water-cyanocobalamine solutions, to generate the desired drug-loaded mPEGA $_{12 \mathrm{a}}-b-\mathrm{ACH}_{36}$ and $\mathrm{mPEGA}_{12 \mathrm{~b}}-b-\mathrm{CHB}_{36}$-based polymersomes. As observed in previous experiments, rapid self-assembly into vesicles with no visible precipitation was observed, suggesting that the method was robust, and that rapid formation of polymersomes under these conditions was not negatively affected by the presence of loaded molecules. The excess of cyanocobalamine was removed by dialysis against water using a 6-8 kDa MWCO membrane, while traces of unentrapped terbinafine were subsequently removed after the dialysis step by centrifugation, followed by filtration through a $0.45 \mu \mathrm{m}$ filter. Drug loading was quantified by RP-HPLC (see ESI $\dagger$ ) on the resulting purified vesicles.

Both mPEGA $_{12 \mathrm{a}}-b-\mathrm{ACH}_{36}$ and $\mathrm{mPEGA}_{12 \mathrm{~b}}-b-\mathrm{CHB}_{36}$, block copolymers displayed a higher cyanocobalamine loading capacity (LC) (Table 2). Interestingly, the acrylamide based polymer mPEGA $_{12 \mathrm{~b}}-b-\mathrm{CHB}_{36}$ showed better drug encapsulation for both the hydrophilic cyanocobalamine and lipophilic terbinafine. Vesicles were analysed by DLS (Fig. 5) to investigate how drug loading affected their size and size distribution. As

Table 2 Drug loading on vesicles (Loading Capacity - LC) and \% relative loading (Encapsulation Efficiency - EE) of $\mathrm{mPEGA}_{12 a}-b-\mathrm{ACH}_{36}$ and $\mathrm{mPEGA}_{12 b}-b-\mathrm{CHB}_{36}$ polymersomes using cyanocobalamin and terbinafine as model drugs

\begin{tabular}{|c|c|c|}
\hline & $\mathrm{mPEGA}_{12 \mathrm{a}}-b-\mathrm{ACH}_{36}$ & mPEGA $_{12 \mathrm{~b}}-b-\mathrm{CHB}_{36}$ \\
\hline Drug/pol. wt $\%^{a}$ & 10 & 10 \\
\hline $\mathrm{LC}_{\text {cyanocobalamin }}$ & $3.9 \pm 0.4$ & $6.0 \pm 0.1$ \\
\hline $\mathrm{EE}_{\text {cyanocobalamin }}$ & $38.7 \pm 3.9$ & $51.9 \pm 1.0$ \\
\hline LC $_{\text {Terbinafine }}$ & $2.47 \pm 0.03$ & $4.7 \pm 2.0$ \\
\hline $\mathrm{EE}_{\text {Terbinafine }}$ & $24.7 \pm 0.28$ & $46.6 \pm 20.4$ \\
\hline
\end{tabular}
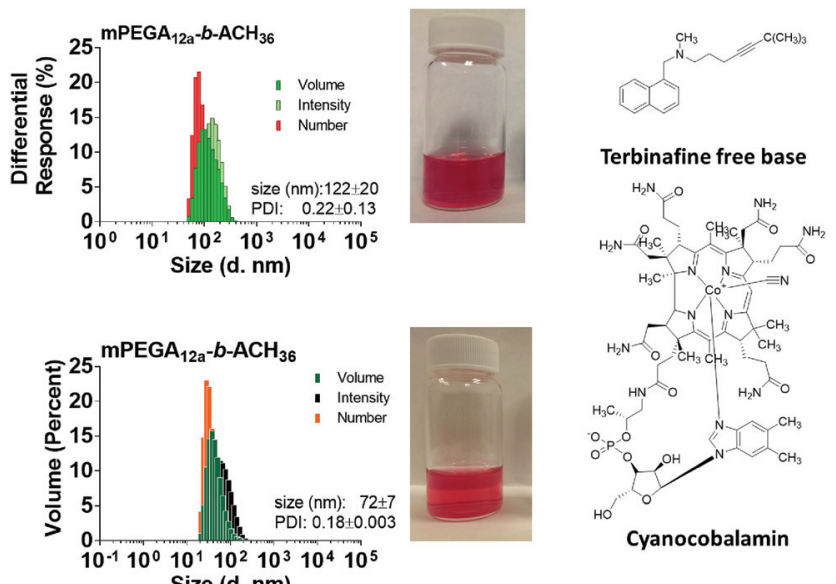

Fig. 5 (A) Loaded polymersomes $\left(1.0 \mathrm{mg} \mathrm{mL}^{-1}\right)$ size distributions of hydrodynamic diameter measured by DLS at $173^{\circ}$ in water at $25^{\circ} \mathrm{C}$. Size $(\mathrm{nm})$ is reported as $z$-average; $(B)$ terbinafine/cyanocobalamine-loaded $\mathrm{mPEGA}_{12 \mathrm{a}}-b-\mathrm{ACH}_{36}$ and $\mathrm{mPEGA}_{12 \mathrm{~b}}-b-\mathrm{CHB}_{36}$ polymersomes. we observed earlier with similar polymers, ${ }^{36}$ loaded polymersomes showed a smaller hydrodynamic radius than the empty assemblies, decreasing to $\sim 72 \mathrm{~nm}$ for $\mathrm{mPEGA}_{12 \mathrm{a}}-b-\mathrm{ACH}_{36}$ while an increase in size to $\sim 80 \mathrm{~nm}$ was observed for mPEGA $_{12 \mathrm{~b}}-b-\mathrm{CHB}_{36}$, as assessed by DLS analysis.

One possible explanation for this phenomenon is a different membrane packing caused by the presence of terbinafine and potential ion pairing between the drug and the weakly acidic 3-chloro-4-hydroxybenzoate of ACH and 3-chloro4-hydroxybenzamide of $\mathrm{CHB}$ polymer repeating units. The observed high entrapment efficiency of cyanocobalamine may be due, at least in part, to additional electrostatic interactions between the partially deprotonated 3-chloro-4-hydroxybenzoate/benzamide repeating units and positively charged $\mathrm{Co}^{\mathrm{III}}$ centres.

\section{Conclusions}

In this study we devised an in line synthetic/assembly strategy which enables facile engineering of drug-loaded polymersomes in only a few hours, starting from acrylate/acrylamide monomers. Using Perrier's one-pot multiple chain extension RAFT polymerisation strategy, amphiphilic mPEGA $_{12 \mathrm{a}}-b-\mathrm{ACH}_{36}$ and $\mathrm{mPEGA}_{12 \mathrm{~b}}-b-\mathrm{CHB}_{36}$ copolymers could be prepared with narrow molecular weight distributions at very high monomer conversion. Reaction conditions - concentration of monomers, CTA: radical initiator molar ratio, nature of the reaction solvent - were optimised to attain good control over the polymerisation process and to avoid intrinsically inefficient purification of reaction intermediates. Importantly, the process was developed using ethanol: water as the reaction medium, in view of a potential application of this process in biological/biomedical settings. The final reaction mixtures could then be directly utilised to assemble well defined polymeric vesicles incorporating both model hydrophilic and hydrophobic drugs in the nanocarriers aqueous lumen and hydrophobic membrane, respectively.

Similarly to click techniques where sub-families of chemical reactions are selected based on a range of favourable features, and PISA, where monomers and macromolecular parameters are chosen to direct supramolecular assembly, our results suggest that when appropriate reagents and conditions are utilised, in line processes could become a viable general route for efficient, scaleable and cost-effective assembly of polymersome nanovectors.

\section{Data access statement}

All raw data created during this research are openly available from the corresponding author (giuseppe.mantovani@nottingham.ac.uk) and at the University of Nottingham Research Data Management Repository (https://rdmc.nottingham.ac.uk/) and all analysed data supporting this study are provided as ESI $\dagger$ accompanying this paper. 


\section{Acknowledgements}

The authors thank the UK Engineering and Physical Sciences Research Council (EPSRC: Grants EP/H006915/1 and EP/ H005625/1 Leadership Fellowship (C. A.); EP/L01646X (A. F. B.); EP/I01375X/1 (G. E. M.)). The authors also thanks the Advanced Microscopy Unit (School of Life Science, University of Nottingham) and Ms Denise McLean for assistance with TEM images acquisition.

\section{Notes and references}

1 L. Zhang and A. Eisenberg, Science, 1995, 268, 1728-1731.

2 D. E. Discher and A. Eisenberg, Science, 2002, 297, 967-973.

3 D. E. Discher and F. Ahmed, Annu. Rev. Biomed. Eng., 2006, 8, 323-341.

4 G. Battaglia, in Nanotechnologies for the Life Sciences, WileyVCH Verlag GmbH \& Co. KGaA, 2007, DOI: 10.1002/ 9783527610419.ntls0250.

5 K. Schillén, K. Bryskhe and Y. S. Mel'nikova, Macromolecules, 1999, 32, 6885-6888.

6 R. Bleul, R. Thiermann and M. Maskos, Macromolecules, 2015, 48, 7396-7409.

7 J. S. Lee and J. Feijen, J. Controlled Release, 2012, 161, 473483.

8 F. Meng, Z. Zhong and J. Feijen, Biomacromolecules, 2009, 10, 197-209.

9 L. Guan, L. Rizzello and G. Battaglia, Nanomedicine, 2015, 10, 2757-2780.

10 R. P. Brinkhuis, F. P. J. T. Rutjes and J. C. M. van Hest, Polym. Chem., 2011, 2, 1449-1462.

11 X. Tian, S. Nyberg, P. S. Sharp, J. Madsen, N. Daneshpour, S. P. Armes, J. Berwick, M. Azzouz, P. Shaw, N. J. Abbott and G. Battaglia, Sci. Rep., 2015, 5, 11990.

12 C. Nardin, J. Widmer, M. Winterhalter and W. Meier, Eur. Phys. J. E: Soft Matter Biol. Phys., 2001, 4, 403-410.

13 R. J. R. W. Peters, M. Marguet, S. Marais, M. W. Fraaije, J. C. M. van Hest and S. Lecommandoux, Angew. Chem., Int. Ed., 2014, 53, 146-150.

14 D. A. Wilson, R. J. M. Nolte and J. C. M. van Hest, Nat. Chem., 2012, 4, 268-274.

15 D. A. Hammer and N. P. Kamat, FEBS Lett., 2012, 586, 2882-2890.

16 N. P. Kamat, J. S. Katz and D. A. Hammer, J. Phys. Chem. Lett., 2011, 2, 1612-1623.

$17 \mathrm{~J}$. Vandenbergh, T. de Moraes Ogawa and T. Junkers, J. Polym. Sci., Part A: Polym. Chem., 2013, 51, 2366-2374.

18 G. Gody, T. Maschmeyer, P. B. Zetterlund and S. Perrier, Macromolecules, 2014, 47, 3451-3460.

19 N. A. Hadjiantoniou, T. Krasia-Christoforou, E. Loizou, L. Porcar and C. S. Patrickios, Macromolecules, 2010, 43, 2713-2720.

20 H. R. Marsden, L. Gabrielli and A. Kros, Polym. Chem., 2010, 1, 1512-1518.
21 L. Messager, J. Gaitzsch, L. Chierico and G. Battaglia, Curr. Opin. Pharmacol., 2014, 18, 104-111.

22 A. Blanazs, J. Madsen, G. Battaglia, A. J. Ryan and S. P. Armes, J. Am. Chem. Soc., 2011, 133, 16581-16587.

23 S. Sugihara, A. Blanazs, S. P. Armes, A. J. Ryan and A. L. Lewis, J. Am. Chem. Soc., 2011, 133, 15707-15713.

24 P. Chambon, A. Blanazs, G. Battaglia and S. P. Armes, Macromolecules, 2012, 45, 5081-5090.

25 C. Gonzato, M. Semsarilar, E. R. Jones, F. Li, G. J. P. Krooshof, P. Wyman, O. O. Mykhaylyk, R. Tuinier and S. P. Armes, J. Am. Chem. Soc., 2014, 136, 11100-11106.

26 V. Ladmiral, M. Semsarilar, I. Canton and S. P. Armes, J. Am. Chem. Soc., 2013, 135, 13574-13581.

27 W. Zhao, G. Gody, S. Dong, P. B. Zetterlund and S. Perrier, Polym. Chem., 2014, 5, 6990-7003.

28 B. Karagoz, L. Esser, H. T. Duong, J. S. Basuki, C. Boyer and T. P. Davis, Polym. Chem., 2014, 5, 350-355.

29 J. Yeow, O. R. Sugita and C. Boyer, ACS Macro Lett., 2016, 5, 558-564.

30 J. Yeow, J. Xu and C. Boyer, ACS Macro Lett., 2015, 4, 984-990.

31 N. J. Warren and S. P. Armes, J. Am. Chem. Soc., 2014, 136, 10174-10185.

32 G. Gody, T. Maschmeyer, P. B. Zetterlund and S. Perrier, Nat. Commun., 2013, 4, 2505-2513.

33 G. Gody, T. Maschmeyer, P. B. Zetterlund and S. Perrier, Macromolecules, 2014, 47, 639-649.

34 G. Gody, R. Barbey, M. Danial and S. Perrier, Polym. Chem., 2015, 6, 1502-1511.

35 F. Mastrotto, S. Salmaso, Y. L. Lee, C. Alexander, P. Caliceti and G. Mantovani, Polym. Chem., 2013, 4, 4375-4385.

36 F. Mastrotto, S. Salmaso, C. Alexander, G. Mantovani and P. Caliceti, J. Mater. Chem. B, 2013, 1, 5335-5346.

37 G. Moad, E. Rizzardo and S. H. Thang, Polymer, 2008, 49, 1079-1131.

38 G. Qi, C. W. Jones and F. J. Schork, Macromol. Rapid Commun., 2007, 28, 1010-1016.

39 C. Capello, U. Fischer and K. Hungerbuhler, Green Chem., 2007, 9, 927-934.

40 F. Huo, X. Wang, Y. Zhang, X. Zhang, J. Xu and W. Zhang, Macromol. Chem. Phys., 2013, 214, 902-911.

41 G. Moad, Y. K. Chong, A. Postma, E. Rizzardo and S. H. Thang, Polymer, 2005, 46, 8458-8468.

42 P. Caliceti and F. M. Veronese, Adv. Drug Delivery Rev., 2003, 55, 1261-1277.

43 A. Sato, S. W. Choi, M. Hirai, A. Yamayoshi, R. Moriyama, T. Yamano, M. Takagi, A. Kano, A. Shimamoto and A. Maruyama, J. Controlled Release, 2007, 122, 209-216.

44 J.-F. Lutz, J. Polym. Sci., Part A: Polym. Chem., 2008, 46, 3459-3470.

45 Although volume fraction is arguably a more appropriate parameter to look at for these types of considerations, weight fraction, easier to calculate, is generally regarded as an acceptable alternative.

46 P. Lim Soo and A. Eisenberg, J. Polym. Sci., Part B: Polym. Phys., 2004, 42, 923-938. 
47 G. Battaglia, C. LoPresti, M. Massignani, N. J. Warren, J. Madsen, S. Forster, C. Vasilev, J. K. Hobbs, S. P. Armes, S. Chirasatitsin and A. J. Engler, Small, 2011, 7, 2010-2015.

48 F. Li, T. Ketelaar, M. A. Cohen Stuart, E. J. Sudholter, F. A. Leermakers and A. T. Marcelis, Langmuir, 2008, 24, 76-82.

49 G.-Y. Liu, L.-P. Lv, C.-J. Chen, X.-S. Liu, X.-F. Hu and J. Ji, Soft Matter, 2011, 7, 6629-6636.

50 H. Fissan, S. Ristig, H. Kaminski, C. Asbach and M. Epple, Anal. Methods, 2014, 6, 7324-7334.

51 X. Liang, G. Mao and K. Y. Ng, J. Colloid Interface Sci., 2004, 278, 53-62.

52 C. M. Hoo, N. Starostin, P. West and M. L. Mecartney, J. Nanopart. Res., 2008, 10, 89-96.

53 E. Tomaszewska, K. Soliwoda, K. Kadziola, B. TkaczSzczesna, G. Celichowski, M. Cichomski, W. Szmaja and J. Grobelny, J. Nanomater., 2013, 2013, 10.
54 W. J. Duncanson, T. Lin, A. R. Abate, S. Seiffert, R. K. Shah and D. A. Weitz, Lab Chip, 2012, 12, 2135-2145.

55 S.-H. Kim, J. W. Kim, D.-H. Kim, S.-H. Han and D. A. Weitz, Microfluid. Nanofluid., 2013, 14, 509-514.

56 F. Ahmed, R. I. Pakunlu, A. Brannan, F. Bates, T. Minko and D. E. Discher, J. Controlled Release, 2006, 116, 150-158.

57 L. Wang, L. Chierico, D. Little, N. Patikarnmonthon, Z. Yang, M. Azzouz, J. Madsen, S. P. Armes and G. Battaglia, Angew. Chem., Int. Ed., 2012, 51, 11122-11125.

58 G. Liu, S. Ma, S. Li, R. Cheng, F. Meng, H. Liu and Z. Zhong, Biomaterials, 2010, 31, 7575-7585.

59 T. Anajafi, M. D. Scott, S. You, X. Yang, Y. Choi, S. Y. Qian and S. Mallik, Bioconjugate Chem., 2016, 27(3), 762-771.

60 J. Thiele, A. R. Abate, H. C. Shum, S. Bachtler, S. Förster and D. A. Weitz, Small, 2010, 6, 1723-1727.

61 X. Wang, L. Wei and L. P. Kotra, Bioorg. Med. Chem., 2007, 15, 1780-1787. 